Journal of Advanced Research in Fluid Mechanics and Thermal Sciences

\title{
Numerical Simulation of Cascade Flow: Vortex Element Method for Inviscid Flow Analysis and Axial Turbine Blade Design
}

\author{
Nono Suprayetno ${ }^{1,3}$, Priyono Sutikno ${ }^{1,2,}{ }^{*}$, Nathanael P. Tandian ${ }^{1,2}$, Firman Hartono $^{1}$ \\ Faculty of Mechanical and Aerospace Engineering, Institut Teknologi Bandung, 40132 Bandung, Indonesia \\ New and Renewable Energy Research Centre LPPM, Institut Teknologi Bandung, 40132 Bandung, Indonesia \\ Directorate General of New Renewable Energy and Energy Conservation, Ministry of Energy and Mineral Resources, 10320 Jakarta, Indonesia
}

\section{ARTICLE INFO}

\section{Article history:}

Received 3 May 2021

Received in revised form 10 July 2021

Accepted 13 July 2021

Available online 5 August 2021

Keywords:

Axial turbine; airfoil; cascade; vortex method

\section{ABSTRACT}

\begin{abstract}
This study aims to design an axial turbine rotor blade and predict the turbine performance at preliminary design stage. Quasi three dimensional method was applied to design including blade to blade flow analysis. The blade profile uses a NACA 0015 airfoil by varying the profile thickness from hub to tip. The profile is divided into eleven segments which has different parameters. The profile was analysed using blade to blade flow/cascade flow analysis called vortex panel method to obtain lift coefficient. The analysis of cascade flow was performed in potential flow and prediction of turbine perfomance is carried out involving common best practice to give drag effect on the blade. The design of the turbine was applied on three different rotors, which also have a different discharge, head, and design rotation. The outer diameter of turbine 1 is 0.65 $\mathrm{m}$, while turbine 2 and turbine 3 have an outer diameter of $0,60 \mathrm{~m}$. The calculation result show that the efficiency of turbines 1,2 , and 3 were $88,32 \%, 89,67 \%$, and $89,04 \%$, respectively.
\end{abstract}

\section{Introduction}

Research on the cascade blade is currently increasing quite rapidly. Cascade blades can be applied to blade design for gas turbine, steam turbine, hydro turbine, pump compressors, blowers, and many other applications. Khattak et al., [1] described the range turbine efficiency for gas turbine, steam turbine and hydro turbine including the advantages and disadvantages. A turbine design tool with high accuracy and efficiency is a challenge in the middle of the era of sophisticated computer technology. Initially, the surface vorticity method was implemented as a tool for analyzing cascade blades. However, Lewis [2] modified it into a tool for designing cascade blades. He used Martensen method derived for the potential flow to calculate the velocity distribution on the airfoil and cascade [3]. Then, back diagonal correction was used to check the design calculation of cascade blades. By adopting the surface vorticity method, the researcher is allowed to design the shape of the airfoil

\footnotetext{
* Corresponding author.

E-mail address: priyonosutikno@gmail.com
}

https://doi.org/10.37934/arfmts.85.2.1423 
and cascade according to desired shape or prescribed pressure distribution. The method of surface vorticity is then called the vortex element method or vortex method.

The vortex method could be implemented in a reverse sense by determining the point of stagnation in the leading edge. This approach can be used to get desired shape. Calculations on airfoils and cascades using the vortex method show promising results compared to the original profile [4]. During its development, the vortex method could be combined with viscous flow and is widely adopted for the design of single airfoil, ground airfoil, airfoil cascade or the impeller using the random walk technique with the Lagrangian scheme [5-8]. The panel method may be applied to increase performance of the sail on the sailboat autonomous part. Sun et al., [8] used the same two airfoils (before and after sail) with various angle of attack. The thicker the airfoil, the farther the airfoil position from the sail and this is a sensitive matter similiar with cascade blade.

The vortex method is a panel method that uses panel discretization during the calculation process. There are several different calculations process for the vortex method, Lewis [2] in his study using vortex constant for the calculations, meanwhile Liu [10] and Boorsma et al., [11] used linear vortex calculation. The difference between the vortex constant and the linear vortex is in the number of matrix coefficients when performing the calculation. Furthermore, vortex method could be optimized to obtain stagger and camber angles on the airfoil cascade to get shock-free conditions [12]. Optimization using the panel method is also widely used, both for potential flow and viscous flow. Hothazie and Mirica [13] and Huang et al., [14] combined the metaheuristic technique with the panel method to obtain a profile shape with a higher lift coefficient than the base profile, while Akram and Kim [15] used another method called Parsec.

The vortex method could be implemented both on airfoil and cascade design. Ng et al., [16] and Yazik et al., [17] investigated the effect of the inlet or angle of attack on the airfoil towards the cascade performance using viscous analysis. However, a study to examine the effect of the inlet or attack angle on the airfoil toward inviscid cascade performance is limited. In general, increasing the inlet or angle of attack will increases the lift coefficient due to lack of skin friction. Susan-Resiga et al., [18], in their study, designed an inviscid cascade at multiple inlet angles with more than $80 \%$ accuracy using the finite element method. However, Rose and Raguraman [19] devised the cascade using the vortex method and used CFD airfoil, but the CFD results show a barrier in the periodic section and make the flow like an isolated airfoil.

This study aims to develop a vortex panel computation program for designing axial turbine blades. The input data for the calculation can be obtained from the triangular velocity and meridional flow analysis. Meridional flow analysis was performed based on the mixed vortex criteria described in the studies of $\mathrm{Ng}$ et al., [15] and Yazik et al., [16]. The criteria for a mixed vortex are a combination of fee vortex and forced vortex. There are three turbine models to be studied, however this research is limited to modeling the rotor blades and predicting turbine performance. Finally, it is hoped that this program can be used as a design tool with good accuracy.

\section{Cascade Blade Design}

\subsection{Construction of Blade Profile Geometry}

Blade profile needs special requirements to provide a stable diffusion flow, especially for the upper surface (suction side). The pressure gradient is always found on the suction side and separation may occur in the viscous flow. On a single airfoil, this could be minimized by injecting the flow into the suction side to reduce aerodynamic losses. Liang et al., [20] showed that this technique could increase $C_{l}$ and reduce $C_{d}$ in NACA 0012 with various angles of attack. 
There are two methods for designing profile shapes, the direct method and the inverse method. In the direct method, the profiles are designed based on experiment or theoretical analysis to identify the most efficient profile shape with the best aerodynamic performance. On the other hand, the inverse method allows the researcher to determine the velocity or pressure distribution on the blade surface.

In this study, the inverse method was adopted to design the profile shape. Construction of blde profile as shown in Figure 1. Profiles are formulated based on half the thickness of the profile base $y_{t}$ perpendicular to the camber line. Then, we construct a circle with radius $1 / 2$ and divide it into segments " $\mathrm{M}$ " to obtain the the segment $\varphi$. Thus, the coordinates of the camber line $x_{c}$ and airfoil coordinate can be calculated as follows:

$\frac{x_{c}}{l}=\frac{1}{2}(1-\cos \phi)$

$x_{a}=x_{c}-y_{t} \sin \theta_{c} \quad$ and $\quad y_{a}=x_{c}-y_{t} \cos \theta_{c} \quad$ for upper surface

$x_{b}=x_{c}-y_{t} \sin \theta_{c} \quad$ and $\quad y_{b}=x_{c}-y_{t} \cos \theta_{c} \quad$ for lower surface

Let $x_{a}$ and $y_{a}$ are coordinate of upper surface of airfoil, $x_{b}$ and $y_{b}$ are cordinate at lower surface and $\vartheta_{c}$ is camber angle. If the arifoil is simetry, then $x_{a}=x_{b}$ and $y_{a}=y_{b}$.

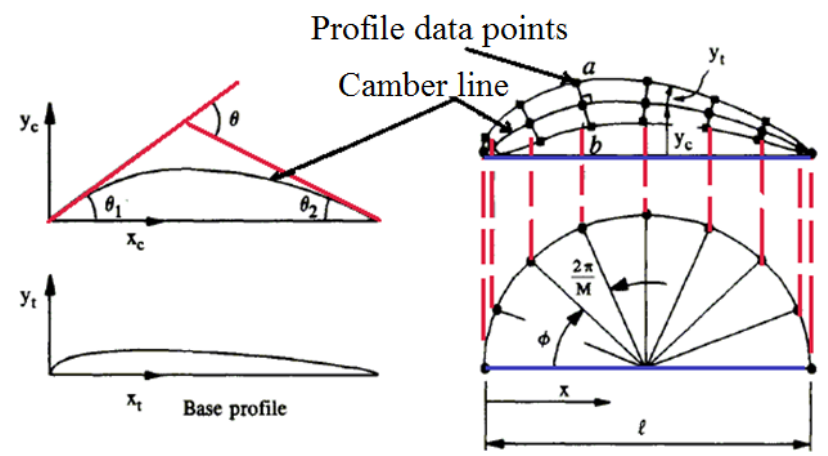

Fig. 1. Construction of blade based on camber line

\subsection{Cascade Blade Parameter}

Cascade blade is consist of infinite number of airfoils with unique parameters. Some of these parameter are pitch chord ratio $t / l$, stagger angle $\lambda$ and camber angle $\vartheta$, inlet angle $B_{1}$ and outlet angle $\boldsymbol{B}_{2}$. These paramater describe in the Figure 2 below. The analysis of the cascade blades can be carried out using the volume control method as shown in Figure 2. Fluid flow through the blade cascade with velocity $W_{1}$ and inlet angle $B_{1}$ will be deflected and produce velocity vector $W_{2}$ and outlet angle $B_{2}$. The flow produces aerodynamic forces on the blade surface as in the cascade velocity triangle in Figure 2. 


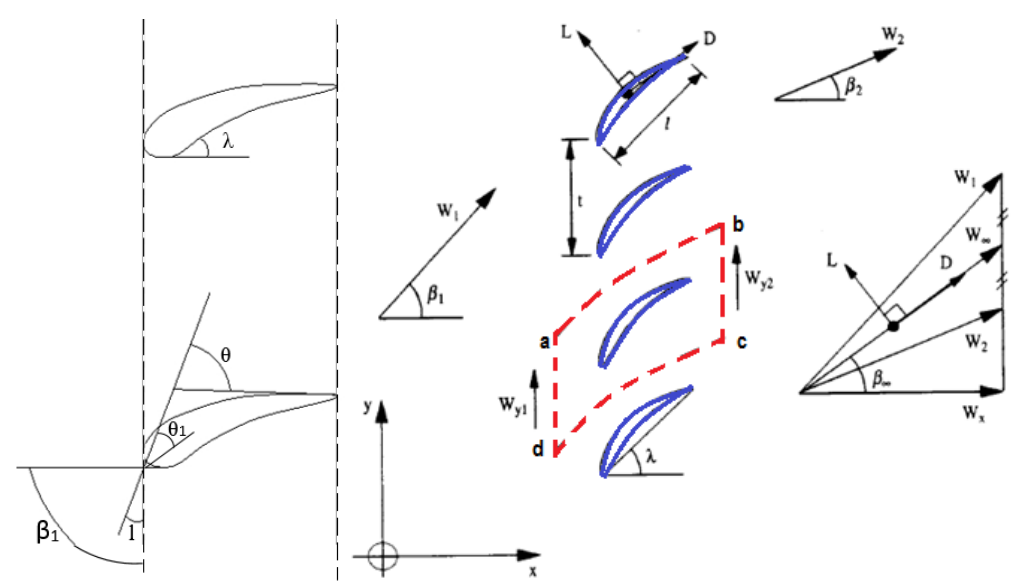

Fig. 2. Geometry and triangle velocity of cascade

\section{Analysis of Cascade Blade}

\subsection{Surface Vorticity Model and Martensen Method}

To apply the panel vortex method on the body surface, the uniform flow with prescribed velocity induced by vortex strength $\gamma(s)$ along with $x$ direction, while $s$ is measured clockwise through body surface. The velocity of the body surface $\left(d q_{m n}\right)$ on point $s_{m}$ induced by the vortex element $\gamma(s) d s_{n}$ at surface $s_{n}$ will be perpendicular to the radial vector $r_{m n}$ (see Figure 3). Following Bio Savart's law

$d q_{m n}=\frac{\gamma(s) d s_{n}}{2 \pi r_{n m}}$

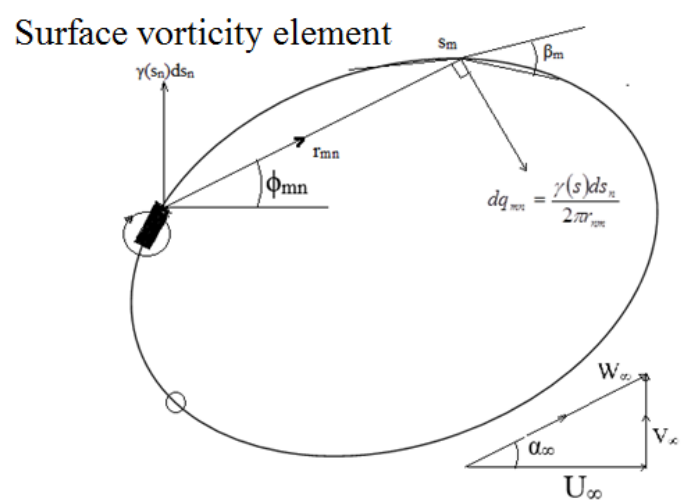

Fig. 3. Surface vorticity model for a twodimensional body

To simplify the calculation, the velocity $d q_{m n}$ is divided into two components in the $x$ and $y$ direction by solving the Eq. (4). The velocity $d q_{m n}$ is assumed to be parallel with the body surface at $m$, where the profile slope is defined as $B m$ at $s_{m}$. Hence the velocities of the $x$ and $y$ directions are obtained as follows

$$
\begin{aligned}
& d U_{s m n}=\frac{\gamma\left(s_{n}\right) d s_{n}}{2 \pi r_{n m}} \sin \varphi_{n m}=\left(\frac{y_{m}-y_{n}}{2 \pi r_{m n}^{2}}\right) \gamma\left(s_{n}\right) d s_{n} \\
& d V_{s m n}=\frac{\gamma\left(s_{n}\right) d s_{n}}{2 \pi r_{n m}} \cos \varphi_{n m}=\left(\frac{x_{m}-x_{n}}{2 \pi r_{m n}^{2}}\right) \gamma\left(s_{n}\right) d s_{n}
\end{aligned}
$$


$U$ and $V$ are the components of velocity parallel to the $x$-axis and $y$-axis. Suppose a parallel flow passes through the body surface $s_{m}$. In this case, the calculation is carried out through a simple method in the form of a straight line or a panel with several pivotal points $M$ located in the center of the panel representing the body surface. The vital point $M$ is represented as several straight line elements of length $\Delta s_{n}$ at the vital point $\left(x_{n}, y_{n}\right)$. Furthermore, the Martensen's integral could transformed into a linear equation by replacing the vortex sheet with some vortex elements $\gamma\left(s_{n}\right) d s_{n}$ on the surface of the object.

$\sum_{n=1}^{M \sum_{m}} K\left(s_{m}, s_{n}\right) \gamma\left(s_{n}\right)=-U_{\infty} \cos \beta_{m}-V \sin$

where $K$ is matrix coupling cooefficient. $K\left(s_{m}, s_{n}\right)$ could modify by linking points $s_{m}$ and $s_{n}$, then,

$K\left(s_{m}, s_{n}\right)=\frac{\Delta s_{n}}{2 t}\left\{\frac{\left(y_{m}-y_{n}\right) \cos \beta_{m}-\left(x_{m}-x_{n}\right) \sin \beta_{m}}{\left(x_{m}-x_{n}\right)-\left(y_{m}-y_{n}\right)}\right\}$

If $m=n$ then the coupling coefficient become:

$K\left(s_{m}, s_{m}\right)=-\frac{1}{2}-\frac{\Delta \beta_{m}}{4 \pi}$

$K\left(s_{m}, s_{m}\right) \approx-\frac{1}{2}-\frac{\beta_{m+1}-\beta_{m-1}}{8 \pi}$

\subsection{Back Diagonal Correction}

The application of the coupling coefficient to airfoil faces two problems, the inaccuracy and the need of Kutta conditions on the trailing edge. In this case, the back diagonal correction could be used to increase the accuracy of the coupling coefficient. Back diagonal correction indicates the mutual impact of vortex elements on the coupling matrix. Figure 4(a) shows the procedure of the back diagonal correction in the coupling matrix.

$K\left(s_{M+1-m}, s_{n}\right)=\frac{1}{\Delta s_{M+1-m}} \sum_{\substack{n=1 \\ n \neq M+1-m}}^{M} K\left(s_{n}, s_{m}\right) \Delta s_{n}$

\subsection{Wilkinson Kutta Condition}

The flow condition strongly influences the total vortex on the airfoil surface at the trailing edge (TE). Therefore, the vorticity could not be determined at the beginning of the calculation. The flow on the upper and lower surface would achieve a trailing edge with velocity $v_{s}=v(s)$. In order to increase the accuracy of the calculation, the fluid flow passing through the body surface must be treated at the same conditions, on velocity and vorticity distribution. It could be achieved by giving the opposite sign for the velocity and vorticity distribution on the upper and lower surface shown in Eq. (12). This condition is known as the Kutta condition, as illustrated in Figure 4(b). 


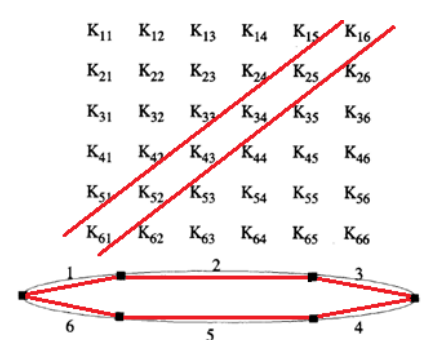

(a)

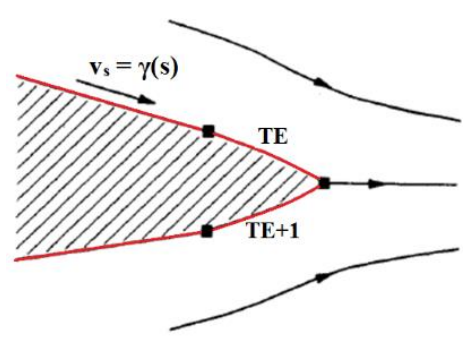

(b)

Fig. 4. (a) Back diagonal correction of matrix coefficient, (b) Kutta condition

$\gamma\left(s_{t e}\right)=-\gamma\left(s_{t e+1}\right)$

The final result of this calculation is the prediction of the lift coefficient $C_{1}$. In this study, the lift coefficient is an important parameter for predicting turbine performance. The pitch chord ratio $t / l$ influences the calculation of the lift coefficient on the cascade. If $t / l>30$, the calculation would be considered a single airfoil. The calculation of the lift coefficient on the cascade is calculated as follows

$C_{l}=2 \frac{t}{l}\left(\tan \beta_{1}-\tan \beta_{2}\right) \cos \beta_{\infty}$

\subsection{Calculation Test of Cascade}

The cascade flows were analyzed using a computation program (author's program) based on the panel vortex method. The authors used the C4 profile to compare the outlet angle (see Table 1) and pressure coefficient distribution $\mathrm{Cp}$ (see Figure 5) with Goestelow's exact solution, surface vortices theory, and Schlichting linearization theory. According to Lewis [21], Goestelow's exact solution could predict the best shape of blade profile through experiments with conformal transformations. However, the author tried to develop a program to approach Goestelow's with more accurate results. Computations were carried out at two different inlet angles, namely $-35^{\circ}$ and $35^{\circ}$, with a camber angle of $70^{\circ}$, a stagger angle of $0^{\circ}$, and a chord pitch ratio of $t / / 0.900364$. The results are presented in Table 1 and Figure 5 with slight differences but are satisfactory. Hence, further studies could use this program to design cascade blades for turbines and compressors.

Table 1

Comparison of cascade analysis calculation test

\begin{tabular}{lll}
\hline Method & $\beta_{1}=35^{\circ}$ & $\beta_{1}=-35^{\circ}$ \\
\hline Exact solution (Goestelow, 1984) & $23.80^{\circ}$ & $24.84^{\circ}$ \\
Surface vorticity theory & $23.85^{\circ}$ & $25.04^{\circ}$ \\
Schlichting linearised theory & $20.28^{\circ}$ & $22.57^{\circ}$ \\
Author program & $23.13^{\circ}$ & $24.38^{\circ}$ \\
\hline
\end{tabular}



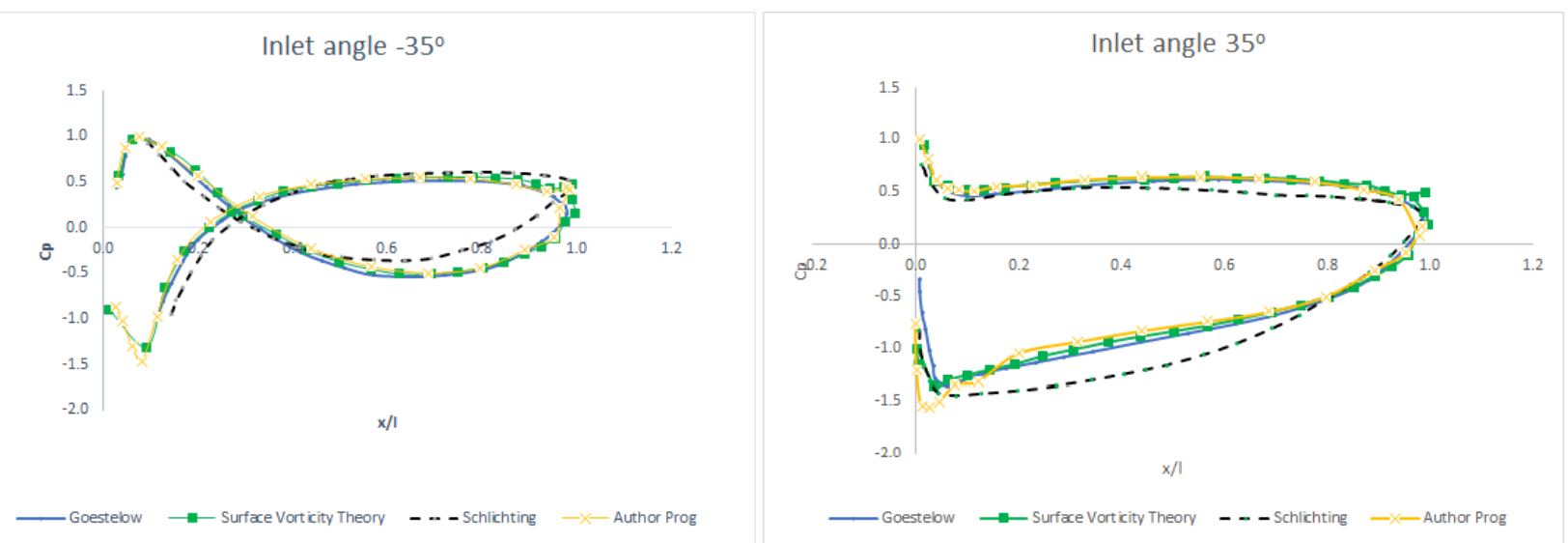

Fig. 5. Cp comparison of several cascade analysis methods

\section{Result and Discussion}

\subsection{Global Parameter Design of Rotor}

This study aims to design and predict the performance of three axial turbine rotors, which are Turbine 1, Turbine 2, and Turbine 3, with different design parameters. The global parameter design of the three axial turbine rotors is shown in Table 2.

Table 2

Design parameters of three axial turbine rotors

\begin{tabular}{llllll}
\hline No. & Name of Turbine & Head $(\mathrm{H})$ & Discharge flow $(\mathrm{Q})$ & Inner Diameter & Outer Diameter \\
\hline 1 & Turbine 1 & $4.5 \mathrm{~m}$ & $1.500 \mathrm{I} / \mathrm{sec}$ & $0.25 \mathrm{~m}$ & $0.65 \mathrm{~m}$ \\
2 & Turbine 2 & $3.5 \mathrm{~m}$ & $2.500 \mathrm{l} / \mathrm{sec}$ & $0.21 \mathrm{~m}$ & $0.60 \mathrm{~m}$ \\
3 & Turbine 3 & $5.0 \mathrm{~m}$ & $1.200 \mathrm{l} / \mathrm{sec}$ & $0.21 \mathrm{~m}$ & $0.60 \mathrm{~m}$ \\
\hline
\end{tabular}

Meridional flow analysis and velocity triangle were performed based on Table 2 . The details of its analysis were not discussed in this paper. Meridional flow analysis and velocity triangle provide $b_{1}, b_{2}$, camber angle $\vartheta$, and stagger angle $\lambda$ as input to the cascade analysis. Afterward, the input data is calculated using the panel vortex method, the results are shown in Table 3.

Table 3 shows the blade profiles on the hub, mean, and tip representing the eleven segments. Initially, each turbine was designed to use five blades, however there is a wide gap in the rotor due to chord length of the turbine blade. There are two ways to calculate the chord length. The first uses $t / I$ as a function of the lift coefficient (see Eq. (13)), and the second uses $t / I$ as a function of the diffusion factor (see Eq. (14)). In this study, the turbine chord length was analyzed by involving the diffusion effect on the blade surface. Therefore, the authors use Eq. (14) for calculated the chord length. The diffusion factor was 0.019 for all blade segments. The shape of the blade profiles on the hub, mean, and tip is shown in Figure 6.

$D F=1-\frac{\cos \beta_{1}}{\cos \beta_{2}}+\frac{\cos \beta_{1}}{2}+\frac{t}{l}\left(\tan \beta_{1}-\tan \beta_{2}\right)$

Figure 6 presents the comparison of the rotor blade profiles on the mean, hub, and tip. It shows that each rotor has different profiles. The profile was sketched into a 3-dimensional shape to create the actual rotor shape and become the basis for virtual and experimental testing. The 3-dimensional rotor blade model is shown in Figure 7. 


\section{Table 3}

Design parameter of stator and rotor blade

\begin{tabular}{llllllllll}
\hline Description & \multicolumn{3}{l}{ Turbine 1} & \multicolumn{3}{l}{ Turbine 2 } & \multicolumn{3}{l}{ Turbine 3 } \\
\hline Section & Hub & Mean & Tip & Hub & Mean & Tip & Hub & Mean & Tip \\
Tangential vel., $c_{\vartheta}(\mathrm{m} / \mathrm{s})$ & 5.98 & 4.49 & 4.29 & 6.66 & 4.66 & 4.28 & 6.78 & 4.67 & 4.28 \\
Axial vel. $c_{x}(\mathrm{~m} / \mathrm{s})$ & 5.31 & 5.31 & 5.31 & 10.52 & 10.52 & 10.52 & 4.84 & 4.84 & 4.84 \\
Inlet Angle, $B_{1}\left({ }^{\circ}\right)$ & -3.2 & -56.79 & -70.67 & -16.98 & -64 & -78.01 & -3.61 & -58.42 & -74.6 \\
Outlet Angle, $b_{2}\left(^{\circ}\right)$ & -46.28 & -64.8 & -75.98 & -54.31 & -71.45 & -80.36 & -50.51 & -68.75 & -78.09 \\
Stagger Angle, $\lambda\left(^{\circ}\right)$ & -24.74 & -57.8 & -73.33 & -35.65 & -67.72 & -79.18 & -27.06 & -63.58 & -76.35 \\
Camber Angle, $\vartheta\left(^{\circ}\right)$ & 64.62 & 21.02 & 7.97 & 56.00 & 11.17 & 3.53 & 70.34 & 15.49 & 5.23 \\
Chord, $I(\mathrm{~mm})$ & 173.25 & 308.59 & 479.48 & 116.53 & 131.91 & 176.44 & 141.57 & 135.73 & 178.26 \\
Number of blades, $z r$ & 5 & 5 & 5 & 5 & 5 & 5 & 5 & 5 & 5 \\
\hline
\end{tabular}

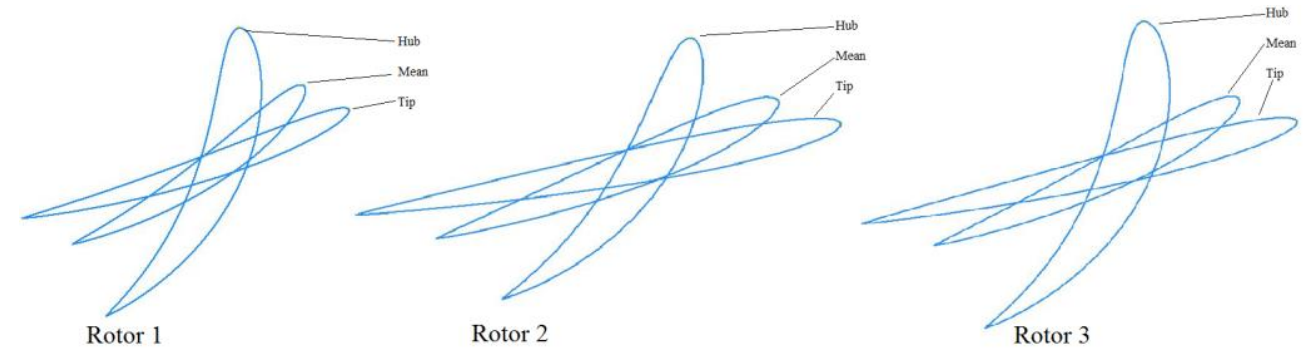

Fig. 6. Profile of Turbine 1, Turbin 2 and Turbine 3 at hub, mean and tip

The rotor model in Figure 7 shows a wide gap between blades. This condition occurred due to the diffusion factor at the design calculation. In this case, the number of blades would be multiplied by two when considering the diffusion factor [22]. Therefore, the rotor would have more blades, as presented in Figure 8.
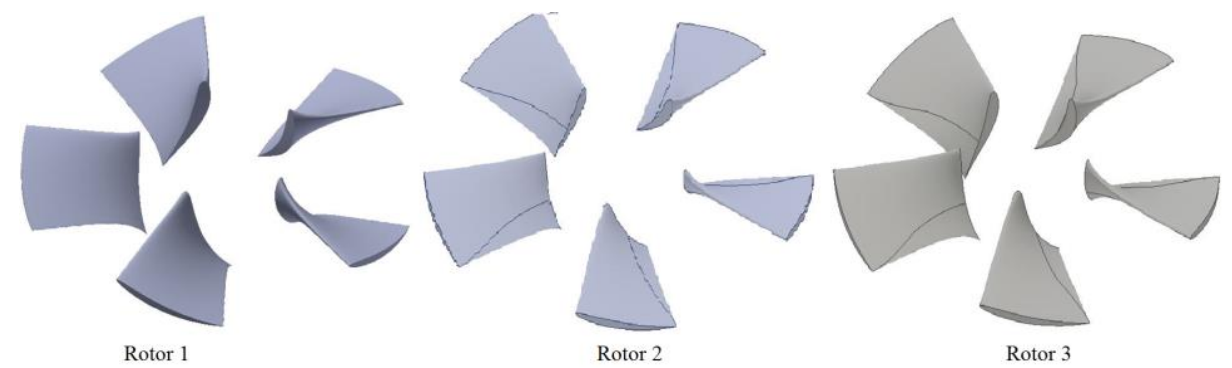

Fig. 7. Rotor model for Turbine 1, Turbin 2 and Turbine 3
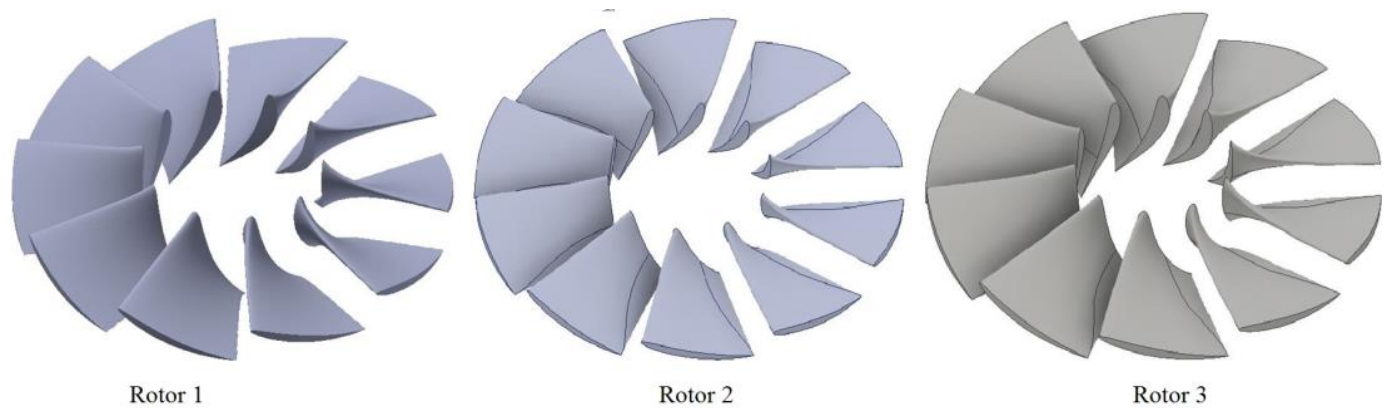

Fig. 8. Final model of Turbine 1 , Turbin 2 and Turbine 3

The rotor, as shown in Figure 8, has more blades compared with Figure 7. It shows that the gap between the blades becomes narrow and would reduce losses. Furthermore, the prediction of rotor performance is carried out based on cascade analysis with several parameters such as $C_{l}$, drag effect 
( $5 \%$ of $C_{l}$ ), and chord length. The results of the rotor performance are quite satisfactory. It shows that each turbine's efficiency is higher than $88 \%$, as presented in Table 4 . However, Further studies require experimental or virtual testing to obtain actual results.

Table 4

Performance of turbine design at preliminary stage

\begin{tabular}{lllll}
\hline No. & Rotor & Power of Fluid, $P_{f}($ Watt) & Power of Turbine, $P_{T}$ (Watt) & Efficiency, $\eta$ \\
\hline 1 & Turbine 1 & $66,098.31$ & $58,375.70$ & $88.32 \%$ \\
2 & Turbine 2 & $85,682.99$ & $76,831.44$ & $89.67 \%$ \\
3 & Turbine 3 & $58,754.05$ & $52,316.95$ & $89.04 \%$ \\
\hline
\end{tabular}

\section{Conclusions}

This study has performed a cascade flow analysis using a computational program and compared it with a similar program. Overall, the results show that the development of the program has been accomplished and satisfying. This program could be used as a design tool for turbomachinery blades in compressors, turbines, and other applications in the preliminary design stage. However, to get more deep results regarding the cascade flow, a three-dimensional test should be carried out using virtual or experimental tests. One of the cheapest ways is through observation using CFD.

\section{Acknowledgement}

The author would like to express special thanks to Pusat Rekayasa Industri LPPM ITB, Ministry of Energy and Mineral Reosurces of Indonesia and Institut Teknologi Bandung for financial support and research.

\section{References}

[1] Khattak, M.A., N. S. Mohd Alib, N. H. Zainal Abidinc, N. S. Azhard and M. H. Omar. "Common Type of Turbines in Power Plant: A Review. " Journal of Advanced Research in Applied Sciences and Engineering Technology 3, no. 1 (2016): 77-100.

[2] Lewis, R. I. "A method for inverse aerofoil and cascade design by surface vorticity." In ASME 1982 International Gas Turbine Conference and Exhibit. American Society of Mechanical Engineers Digital Collection, 1982. https://doi.org/10.1115/82-GT-154

[3] Martensen, Erich. The Calculation of the Pressure Distribution on a Cascade of thick Airfoils by means of Fredholm Integral Equations of the Second Kind. National Aeronautics and Space Administration; for sale by: National Technical Information Service, Springfield, Va., 1971.

[4] Ismail, Kamal A. R., and, Célia V. A. de G. Rosolen. "Application of the Vortex Distribution to Genrate Airfoils and Casacades." In Proceedings of 20th International Congress of Mechanical Engineering. ABCM, 2009.

[5] de Oliveira, Leandro Silva, Luiz Antonio Alcântara Pereira, and Miguel Hiroo Hirata. "Numerical Simulation of AirfoilVortex Cloud Interaction in Ground Effect." In Proceedings of 18th International Congress of Mechanical Engineering. ABCM, 2005.

[6] de Oliveira, Leandro Silva, Luiz Antonio Alcântara Pereira, Miguel Hiroo Hirata, and Nelson Manzanares Filho. "Numerical Modelling Of The Airfoil-Vortex Cloud Interaction." In Proceedings of the 10th Brazilian Congress of Thermal Sciences and Engineering (ENCIT 2004). Braz. Soc. of Mechanical Sciences and Engineering, ABCM, 2004.

[7] Pereira, Luiz Antonio Alcântara, and Miguel Hiroo Hirata. "Study Of Linear Cascade-Vortex Cloud Interaction." In Proceedings of 18th International Congress of Mechanical Engineering. ABCM, 2005.

[8] Pereira, Luiz Antonio Alcântara, and Miguel Hiroo Hirata. "Development Of The Vortex Method For Centrifugal Impeller Applications." In Proceedings of 20th International Congress of Mechanical Engineering. ABCM, 2009.

[9] Sun, Zhao-yang, Jian-cheng Yu, Ai-qun Zhang, and Qian-long Jin. "Analysis of influencing factors on lift coefficients of autonomous sailboat double sail propulsion system based on vortex panel method." China Ocean Engineering 33, no. 6 (2019): 746-752. https://doi.org/10.1007/s13344-019-0073-x 
[10] Liu, Han. "Linear strength vortex panel method for NACA 4412 Airfoil." In IOP Conference Series: Materials Science and Engineering, vol. 326, no. 1, p. 012016. IOP Publishing, 2018. https://doi.org/10.1088/1757899X/326/1/012016

[11] Boorsma, K., M. Hartvelt, and L. M. Orsi. "Application of the lifting line vortex wake method to dynamic load case simulations." In Journal of Physics: Conference Series, vol. 753, no. 2, p. 022030. IOP Publishing, 2016. https://doi.org/10.1088/1742-6596/753/2/022030

[12] Muis, Abdul, Priyono Sutikno, Aryadi Soewono, and Firman Hartono. "Optimal Design of Two-Dimensional Cascade with Shock-Free Inflow Criterion." International Journal of Fluid Machinery and Systems 9, no. 4 (2016): $362-369$. https://doi.org/10.5293/IJFMS.2016.9.4.362

[13] Hothazie, Mihai-Vladut, and Matei Mirica. "Low-speed airfoil optimization using constrained differential evolution." INCAS Bulletin 12, no. 4 (2020): 83-94. https://doi.org/10.13111/2066-8201.2020.12.4.8

[14] Huang, Xinxiang, Xiaofeng Guo, and Ren Zhang. "Design of The Thick Wind Turbine Airfoil Based on An Improved MOPSO Algorithm." In IOP Conference Series: Earth and Environmental Science, vol. 619, no. 1, p. 012056. IOP Publishing, 2020. https://doi.org/10.1088/1755-1315/619/1/012056

[15] Akram, Md Tausif, and Man-Hoe Kim. "Aerodynamic shape optimization of NREL S809 airfoil for wind turbine blades using reynolds-averaged navier stokes model-Part II." Applied Sciences 11, no. 5 (2021): 2211. https://doi.org/10.3390/app11052211

[16] Ng, Yu Han, Wah Yen Tey, Lit Ken Tan, Gerald Pacaba Arada, and M. W. Muhieldeen. "Numerical Examination on Two-Equations Turbulence Models for Flow Across NACA 0012 Airfoil with Different Angle of Attack." CFD Letters 12, no. 2 (2020): 22-45.

[17] Yazik, Muhamad Hasfanizam Mat, Masaaki Tamagawa, Mohamed Thariq Hameed Sultan, and Adi Adzrif. "Computational Study on Aerodynamic Characteristics and Behaviour of S5010 Airfoil." Journal of Advanced Research in Fluid Mechanics and Thermal Sciences 66, no. 1 (2020): 42-52.

[18] Susan-Resiga, R., Sebastian Muntean, and Ioan Anton. "Numerical Analysis of Cascade Flow. Part I: Finite Element Analysis of the Inviscid Flow." In 5th International Conference on Hydraulic Machinery and Hydrodynamics, Timisoara, pp. 159-166. 2000.

[19] Rose, J. Bruce Ralphin, and M. Raguraman. "Numerical Investigation of Aerofoil Cascade and Tandem Cascade Using Vortex Panel Method." Asian Engineering Review 2, no. 2 (2015): 23-29.

[20] Liang, Chua Bing, Akmal Nizam Mohammed, Azwan Sapit, Mohd Azahari Razali, Mohd Faisal Hushim, Amir Khalid, and Nurul Farhana Mohd Yusof. "Numerical Simulation of Aerofoil with Flow Injection at the Upper Surface." CFD Letters 12, no. 1 (2020): 98-110.

[21] Lewis, Reginald Ivan. Turbomachinery performance analysis. Butterworth-Heinemann, 1996.

[22] Lewis, Reginald Ivan. "Vortex Element methods for Fluid Dynamic Analysis of Engineering Systems." Cambridge University Press (1991). https://doi.org/10.1017/CBO9780511529542 